Ann. Parasitol. Hum. Comp., 1993, $68: \mathrm{n}^{\circ} 1,11-23$.

Mémoire.
Key-words: Pirhemocyton. Toddia. Virus. Erythrocytes. Geckoes. Agama spp. Skinks. Frogs. Hematology. Hematopoiesis.

Mots-clés : Pirhemocyton. Toddia. Érythrocytes. Geckos. Agama spp. Scinques. Grenouilles. Hématopoï̀se.

\title{
ERYTHROCYTIC VIRAL INFECTIONS OF LIZARDS AND FROGS: NEW HOSTS, GEOGRAPHICAL LOCATIONS AND DESCRIPTION OF THE INFECTION PROCESS
}

\author{
I. PAPERNA, A. P. ALVES DE MATOS
}

\begin{abstract}
SUMMARY
Pirhemocyton infections are reported from erythrocytes of six species of gecko from Australia, one each from France and Cisjordan, and from two Agama spp. and one skink from Africa. Toddia is reported from a Thai and a South African frog. Infection in all geckoes involved the formation of a vacuole in the erythrocyte. This vacuole was lacking in infections of agamids and skinks. In was also lacking in Toddia infections, but in these, there was a formation of a crystalloid body. Viral inclusions were largest in immature erythrocytes, and were larger in Toddia than in Pirhemocyton. Pathological changes in the infected erythrocytes
\end{abstract}

and the course of infection in lizards and frogs are reported and discussed. Infected cells gradually degenerate either by shrinkage or through vacuolation. Loss of the infected cell was compensated for by proliferative hematopoiesis. Critical hematological conditions develop when many or all erythrocytes became infected. Accelerated hematopoiesis led to recovery, whereby the infection regressed and infected erythrocytes were replaced by new, uninfected ones. Infection was either eliminated, or latent at a low level, with the potential to cause later relapse.

RÉsumÉ : Infections par des virus érythrocytaires de lézards et de grenouilles : nouveaux hôtes et localisations géographiques; description du processus infectieux.

Des infections érythrocytaires par Pirhemocyton sont signalées chez 6 espèces de geckos en Australie, une en France, une en Cisjordanie, deux Agama spp. et un scinque en Afrique. Toddia est signalé chez une grenouille en Thailande et chez une autre en Afrique du Sud.

Chez tous les geckos une vacuole est formée dans l'érythrocyte. Elle est absente dans les infections des agames et des scinques. Elle manque également dans les infections par Toddia où elle est remplacée par un corps cristalloïde. Les inclusions virales sont les plus grandes dans les globules rouges immatures et sont plus grandes pour Toddia que pour Pirhemocyton. Les altérations patho- logiques des érythrocytes infectés ainsi que l'évolution de l'infection chez les lézards et les grenouilles sont décrites et discutées. Les cellules infectées dégénèrent progressivement, soit en se condensant soit en se vacuolisant. La disparition des cellules infectées est compensée par une prolifération hématopoïétique. Une crise hématologique survient lorsque de nombreux (ou tous) les érythrocytes sont infectés. L'accélération de l'hématopoïèse entraîne la guérison au fur et à mesure de la diminution de l'infection et du remplacement des érythrocytes infectés par des cellules saines. L'infection est tantôt éliminée, tantôt elle évolue à bas bruit avec parfois des rechutes tardives.

\section{INTRODUCTION}

Red inclusions seen in Giemsa-stained blood films of amphibians and reptiles since the beginning of this century were given the generic names Toddia França, 1912 and Pirhemocyton Chatton and Blanc, 1914. Similar inclusions in erythrocytes of marine fish were referred to as piscine, or viral erythrocytic necrosis (PEN or VEN respectively; Smail, 1982). Pirhemocyton inclusions of reptiles, Toddia of frogs and of PEN-affected fish erythrocytes have since been shown by electron microscopy (TEM) to be virosomes

Department of Animal Sciences, Faculty of Agriculture, Hebrew University of Jerusalem, Rehovot, 76-100, Israel, and Anatomic Pathology Department of the Curry Cabral Hospital and SBFD section of the Zoology and Anthropology Department, University of Lisbon, Portugal.

Accepté le : 22 septembre 1992. of large (190-400 $\mu \mathrm{m})$ icosahedral DNA viruses (Stehbens and Johnston, 1966; Sousa and Weigl, 1976; Walker and Sherburne, 1977). Johnston (1975) listed 35 hosts for Pirhemocyton and 15 for Toddia. In this communication, we report new hosts and geographical locations of erythrocytic viral Pirhemocyton and Toddia-like infections, and describe the course of these infections in their respective hosts.

\section{MATERIALS AND METHODS}

A search for blood parasites in amphibia and reptiles was carried out in northern Queensland (August, 1986, July-September, 1988), in South Australia (October, 1988), Thailand (NovemberDecember, 1988) and South Africa (July, 1989). Also examined were: Tarentola mauritanica captured at the outskirts of Banyulssur-Mer, southern France in June, 1989, and Ptyodactylus hasselquistii from the escarpment along the Lower Jordan Valley, Cisjordan. The latter were studied in the framework of a long-term 
study, during 1990-1991 on transmission of blood parasites in these gecko populations in two selected natural habitats. Lizards found infected were retained in captivity and their blood was repeatedly examined until they had completely recovered from the viral erythrocytic infection. Hematological data from 46 naturally infected $P$. hasselquistii, obtained during 1990-1991, were available for this study. Of these, 22 were maintained in captivity to follow up the course of infection. Only 1-5 naturally infected specimens were available for study from all other lizard species or frogs. Blood from live lizards was obtained by clipping the finger tip. Air dried smears were fixed in absolute methanol and stained for 1 hour in $8 \%$ Giemsa diluted in $\mathrm{pH}$ 7-7.2 phosphate buffer. Differential counts were made per at least 500 erythrocytes in high infection ( $>50 \%$ of the erythrocytes), and per 2,000 $-5,000$ in low infection $(0-49 \%)$. Nomenclature of immature erythrocytes is according to Hawkey and Dennett (1989).

\section{RESULTS}

Among the lizards, two characteristic forms of erythrocytic infection were found: $a$ ) with a vacuole (= albuminoid body of Stehbens and Johnston, 1966) like in the type species of Pirhemocyton - P. tarentolae Chatton et Blanc 1914, in geckoes (Geckonidae) and $b$ ) without vacuole, in agamid lizards (Agama spp.) and skinks. In all the hosts, virions were visible as small purple dots in the erythrocytic cytoplasm.

Vacuole forming infections were found in the following hosts and localities [No. infected/No. examined, year]:

- Heteronotia binoei (Gray, 1845), Townsville and Charters Towers surroundings, north-eastern Queensland, Australia (Fig. $1 \mathrm{~A}, \mathrm{~B}$ ) $[3 / 29,1986 ; 2 / 47,1988]$;
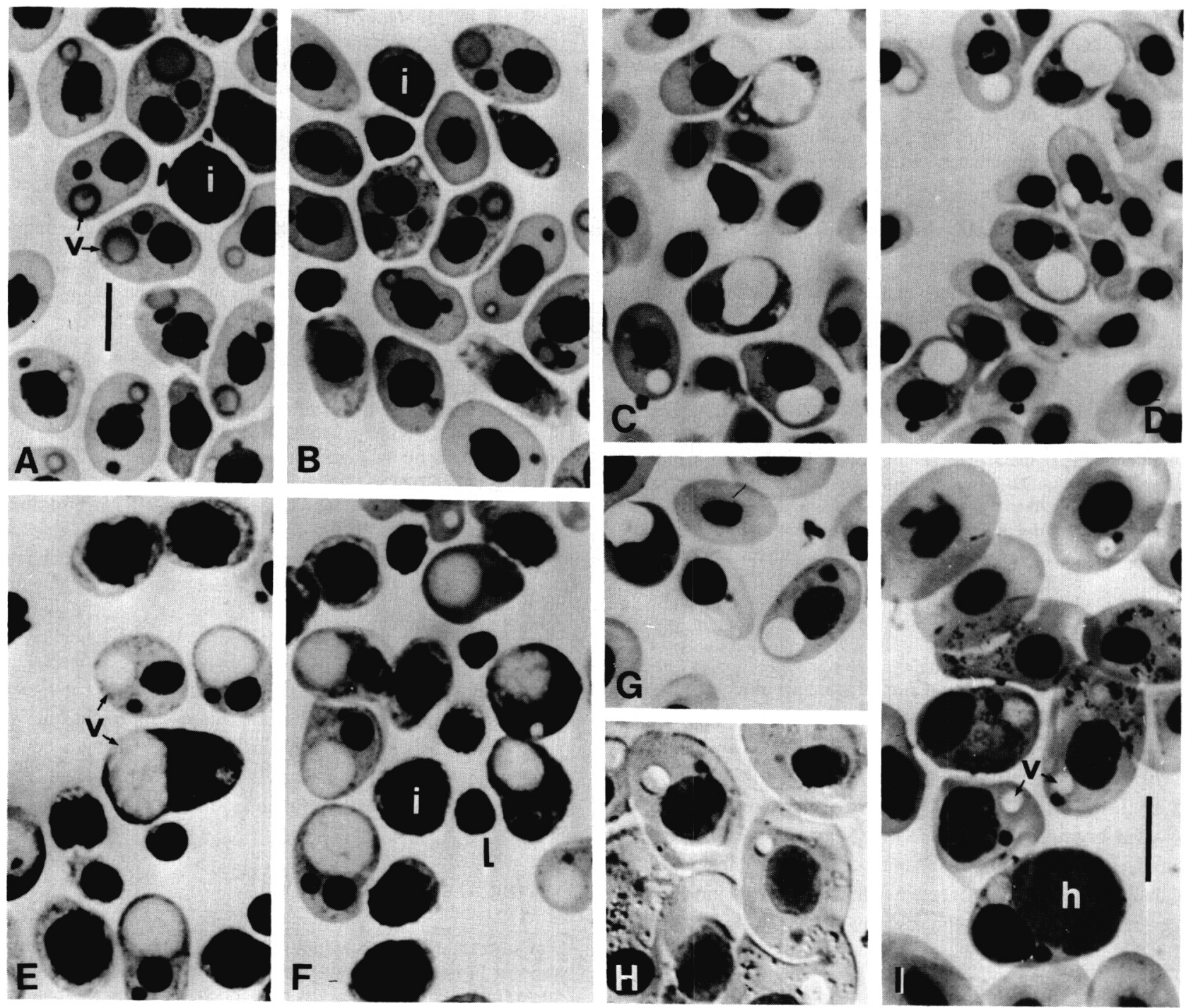

FIG. 1. - Pirhemocyton infection in Australian geckoes: $A, B$, Heteronotia binoei, heavy infection and immature erythrocytes (i), v, vacuole; $C, D$, Oedura rhombifer; E, F, Phyllodactylus marmoratus, crisis stage with immature erythrocytes (i) and lymphocyte (l) proliferation: $G$, Gehyra variegata; $H, I$, Gehyra australis concomitant infection with Haemoproteus gehyrae $(\mathrm{h})$, v, vacuole $(\mathrm{H}$, using Nomarski). Bar $=10 \mu \mathrm{m}(A-G$, same scale $)$. 
- Oedura rhombifer (Gray, 1845), Townsville, northeastern Queensland, Australia (Fig. 1 C, D) [1/29, 1988];

- Phyllodactylus marmoratus (Gray, 1845), Maccles Fields, South Australia (Fig. 1 E, F) [2/6; 1988];

- Gehyra variegata (Dumeril and Bibron, 1836), Julia creek, north-western Queensland, Australia (Fig. 1 G) [1/15, 1988];

- Gehyra cf. variegata, Cambrai, South Australia [1/14, 1988];

- Gehyra australis (Gray, 1845), Townsville, northeastern Queensland, Australia (Fig. 1 H, I) $[1 / 22,1986$; $0 / 25,1988]$;

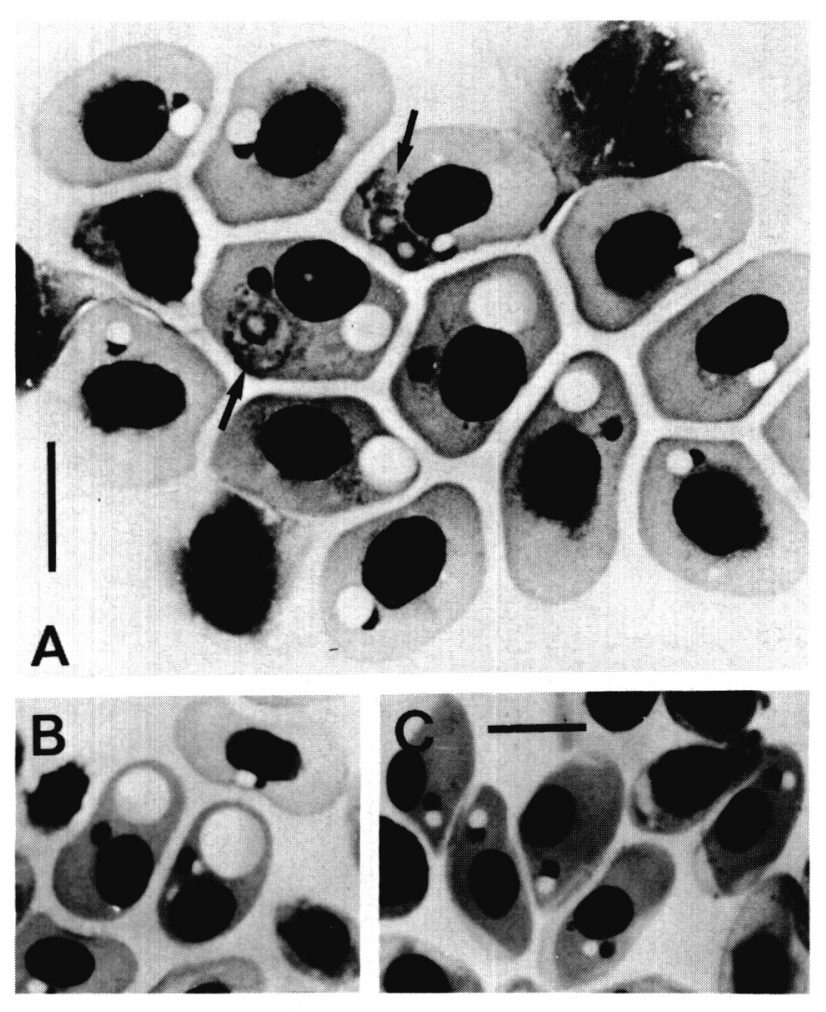

FIG. 2. - Phirhemocyton infection in Tarentola mauritanica: A, concomitant infection with Haemoproteus tarentolae (arrow); $B, C$, infected erythrocytes with small and large vacuoles. Bar $=10 \mu \mathrm{m}(B-C$, same scale).

- Tarentola mauritanica L. 1758, Banyuls-sur-Mer, France (Fig. 2) $[3 / 25,1988)$. Presence of infection in T. mauritanica from Banyuls-sur-Mer has been previously reported by Rioux et al. (1979);

- Ptyodactylus hasselquistii (Donndorf, 1789) Lower Jordan Valley, Cisjordan (Fig. 3) [46/410, 1990/91].

The location of the virosome in the erythrocytes was variable except in $T$. mauritanica and $P$. hasselquistii, where virosomes were often found adjoining the vacuole (Figs. $2 C, 3 G$ ). The vacuoles in all geckoes except $P$. hasselquistii were droplet-like (Fig. $3 D, E$ ). In the latter, they seemed to be membrane-bound and to have accumulated virions.

Infections not accompanied by a vacuole were found in:

- Mabuya capensis (Gray, 1831), Fauresmith, SW Orange Free State, South Africa (Fig. 4 A, B) [2/8, 1989];

- Agama atra (Daudin, 1802), southeast and southwest of the Orange Free State, including areas at elevations of 2,500 m, South Africa (Fig. 4 C, E-H) [4/33, 1989];

- Agama impalearis (Boettger, 1874), southern Morocco (Fig. 4 D, I-L) [1/1, 1989].

The infection of frog erythrocytes was characteristic of Toddia: formation of one or several crystalloid bodies, but no formation of a vacuole (Fig. 5). Like in the reptilian infections, virions could be observed in the erythrocytic cytoplasm. Infection was found in:

Limnonectes (Bourretia) sp. [cf. pileatus], Doi Tai forest, North Thailand (Fig. 5 A-C) [1/1, 1989];

- Ptychadena anchietae (Bocage, 1867), northern Transvaal, South Africa (Fig. 5 D-J) [1/3, 1989].

\section{Host CELLS}

Infections were only found in the blood erythrocytes, in immature (proerythroblasts, basophilic and polychromophilic erythroblasts and pre-erythrocytes) and mature cells. In both lizard and frog infections, inclusions ( = viral factory, or virosomes) were larger in immature erythrocytes than in mature ones (Tables I, II; Figs. 3 A, B, 4 E, I), and were largest in Toddia infections (Fig. 5 F). Inclusions in newly matured erythrocytes were larger than in aged erythrocytes (Figs. $3 \mathrm{~J}, 5 \mathrm{E}$ ). Larger inclusions had a less condensed matrix. The crystalloid bodies of Toddia occurred in both immature and mature infected erythrocytes (Fig. $5 B, C, E, F$ ). Viral particles were detected in the cytoplasm, except in $P$. hasselquistii where they also accumulated in the vacuole. Virions could be detected in the cytoplasm of the infected erythrocytes at an early stage of infection. In $P$. hasselquistii vacuoles larger than $3 \mu \mathrm{m}$ in diam. already contained virions (Fig. $3 \mathrm{D}$ ). In the infected erythrocytes of $P$. hasselquistii vacuoles seemed to develop only after virosome appearance, when virions were already present in the cytoplasm (Fig. $3 \mathrm{H}$ ). In all other geckoes, virosome and vacuole developed simultaneously (Fig. $1 \mathrm{~A}$, $2 C$ ), while free virions in the cytoplasm appeared later on. Vacuoles in all infected geckoes occurred in the erythrocyte nucleus as well. Vacuoles in immature and mature infected erythrocytes, in $O$. rhombifer and $P$. marmoratus in particular, grew immensely, up to $12 \mu \mathrm{m}$ in diam., displaced the nucleus and caused the cell to swell (Table I; Fig. 1 C-F).

Infected cells in all hosts degenerated through shrinkage and atrophy, to small round bodies, half the size (or smaller) of a normal cell ( $>14 \mu \mathrm{m}$ in diam.; Figs. $1 \mathrm{C}$, 

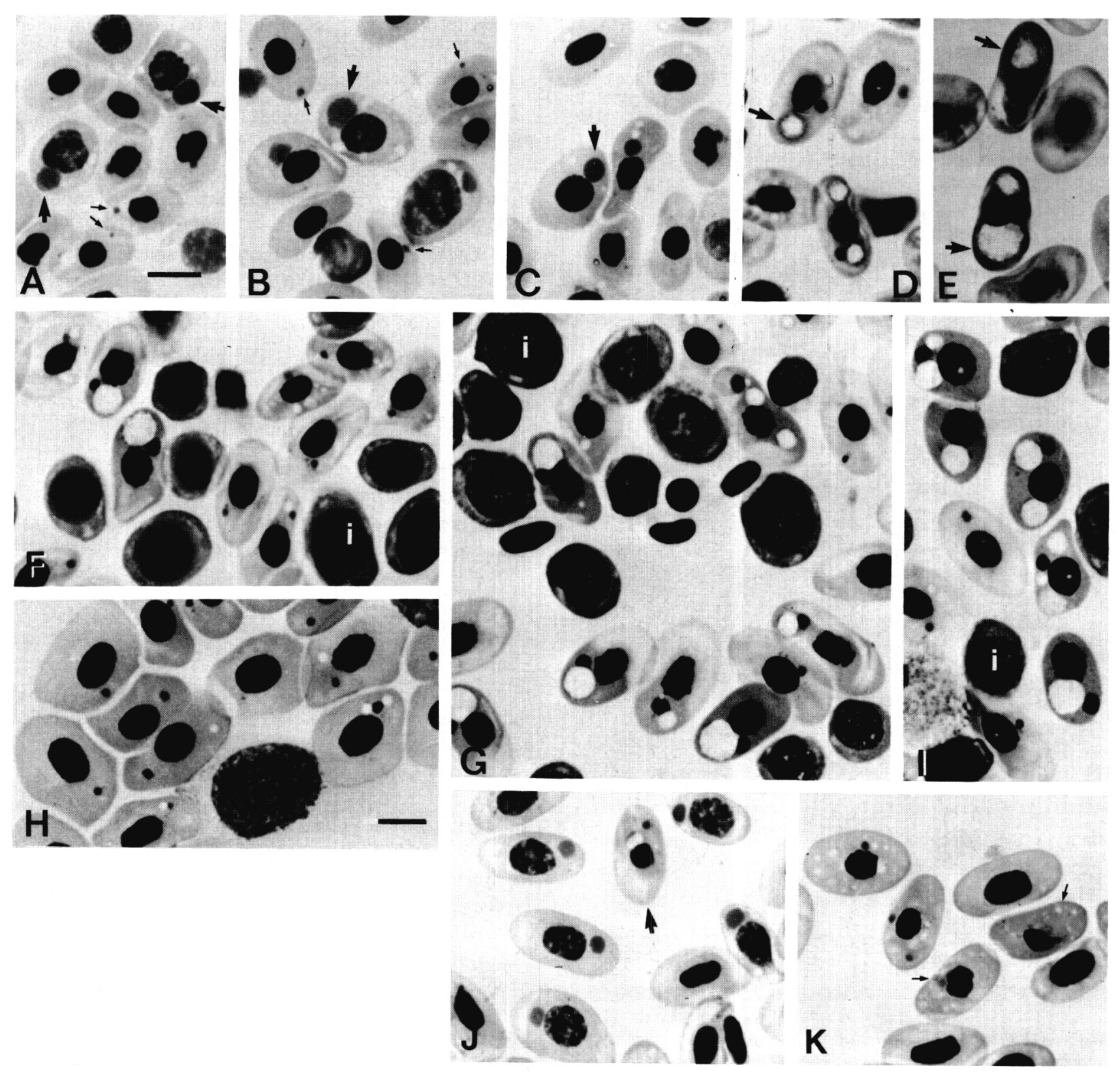

\section{E}

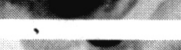

Fig. 3. - Pirhemocyton infection in Ptyodactylus hasselquistii erythrocytes: $A$ - $C$, large virosomes (bold arrows) in pre and young erythrocytes, and a very small inclusion (fine arrows) in mature cells (early acute stage); $D, E$, infection accompanied by large vacuoles (pre-crisis stage), note virions in the vacuole (arrow); $F, G$, crisis stage, abunding with immature erythrocytes; $H$, early acute stage, with few or no vacuoles; $I$, acute stage with several vacuoles appearing in the infected cells; $J$, relapse after crisis, with large inclusions in young erythrocytes (arrow, infected aged erythrocyte); $K$, infected aged erythrocytes showing cytoplasmic vacuolization, arrow, disaggregating viral inclusion. Bar $=10 \mu \mathrm{m}(A-G, I-K$, same scale).

$F, 3 J, 4 D, K, L, 5 C, G)$. In $A$. impalearis they also degenerated into a spindle shape (Fig. $4 \mathrm{~K}, \mathrm{~L}$ ). In chronic infections of aged erythrocytes, the cytoplasm became heavily vacuolated (Fig. $3 \mathrm{~K}$ ), and nuclei died through pyknosis or karyorrhexis. Thickening of the erythrocytic wall membrane occurred most notably in infected immature erythrocytes of agamid lizards (Fig. 4 E-H). Hypertrophic or atrophic cells were rare in T. mauritanica infections.
THE PROCESS OF INFECTION

AND heMaCyTOLOGiCAL CHANGES

Heavy infections, involving $>50 \%$ of the erythrocytes with elevated hematopoiesis were found in $P$. hasselquistii (Figs. 6-9), G. australis (Fig. 10), H. binoei, P. marmoratus, A. impalearis (Fig. 11) and in the frog P. anchietae. In $O$. rhombifer and another $H$. binoei, despite high infec- 

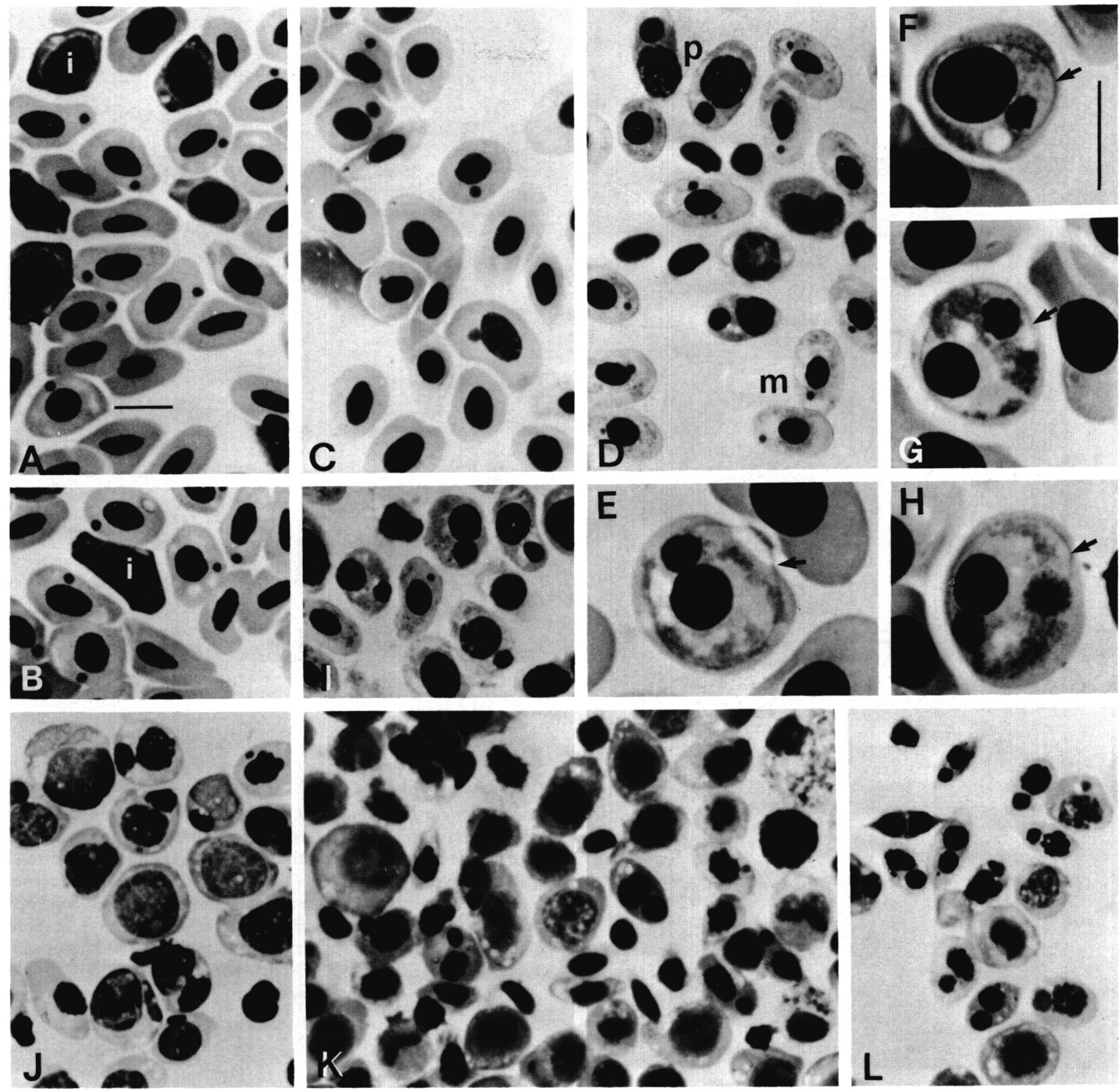

FIG. 4. - Pirhemocyton in skinks and agamid lizards: $A, B$, infection in Mabuya capensis, moderate infection with proliferation of immature erythrocytes; $C$, mild infection in Agama atra; $D$, acute infection in $A$. impalearis: note large inclusion in pre-erythrocytes (p) and small inclusion in mature erythrocytes (m); $E-H$, rounded immature infected erythrocyte of $A$. atra with large virosome and thickened wall (arrow); $I$, sub crisis stage in $A$. impalearis with increased numbers of infected immature erythrocytes; $J$, crisis stage infection in $A$. impalearis with immature erythrocyte proliferation; $K, L, A$. impalearis blood picture at death, note immature and degenerate spindle shaped erythrocytes. Bar $=10 \mu \mathrm{m}(A-D, I-L$, and $E-H$, sames scales $)$.

tion, levels of immature erythrocytes remained low (Fig. 12). The three studied T. mauritanica demonstrated variable levels of erythrocytic infection, and immature cells undergoing variable degrees of proliferation (Figs. 13-15). Moderate infections, 35-50\%, with no anemia was found in Gehyra variegata, and in $G$. cf. variegata. In M. capensis there was an increase in the ratio of immature erythrocytes, whereas the level of infection of mature erythrocytes never exceeded $26 \%$ (Fig. 4 A, B).

The course of infection and the resulting hemacytological changes were reconstructed from a follow up of natural infections in captive animals, and from haemato- 

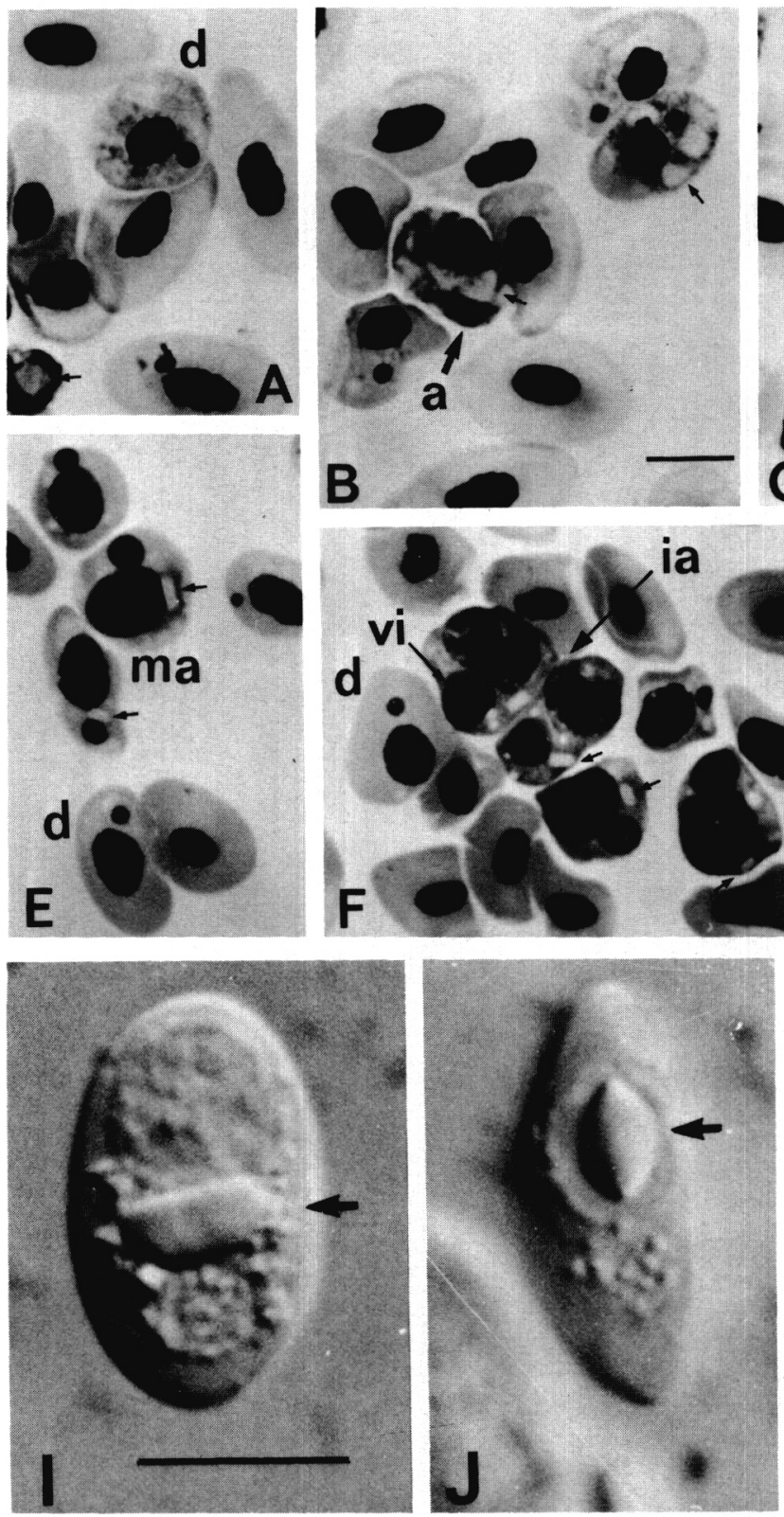

logical data of blood films taken from free ranging infected hosts. Data from P. hasselquistii provided the greatest source of information on the course of infection (Figs. 6-9). Cytological analysis of blood films from all other available infected hosts (geckoes, agamids, skinks and frogs) however, suggest a similar infection process.

\section{ACUTE INFECTION}

Initial stages of infection were recognized only when followed by an acute stage: in this early stage of acute infection like in the latent chronic stage (Fig. $3 \mathrm{H}$ ), only a frac-
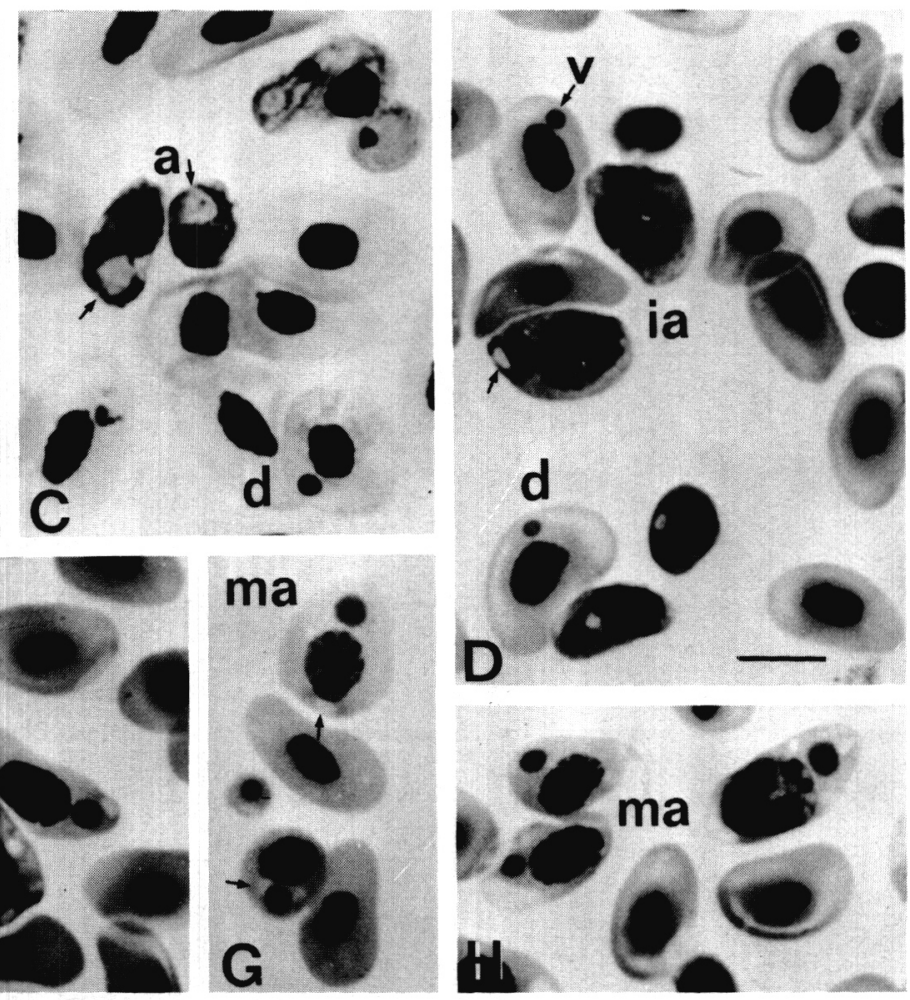

Fig. 5. - Toddia infection from frogs: $A-C$, infection in blood of a Limnonectes sp., small inclusions in mature erythrocytes (d) and large inclusion accompanied with crystalloid body formation (arrow) in immature erythrocytes (a); $D-H$, infection in blood of Ptychadena anchietae: small inclusions in mature erythrocytes (d) and large inclusions (vi) accompanied crystalloid bodies (arrows) in both mature (ma) and immature cells (ia); $I, J$, infected erythrocytes with crystals (arrows) viewed live by Nomarski microscopy. Bars $=10 \mu \mathrm{m}$ ( $A-C, D-H$ and $I, J$, sames scales).

tion of the erythrocytes contained a viral inclusion with no, or only a very small vacuole. Very few immature infected erythrocytes occured (Fig. 6: 28/9-8/10).

Infection advanced till all mature erythrocytes became infected (Fig. 6). In the infected gecko erythrocytes, vacuoles gradually reached their maximum size (Figs. $1 \mathrm{~A}$ $F, 2 A, 7,8$ ). In $P$. hasselquistii, but only rarely in other geckoes, several smaller vacuoles were sometimes formed, instead of the large one (Fig. $3 \mathrm{I}$ ). The proportion of infected immature cells in all lizards was, at this stage of the infection, sometimes the same, but usually lower than that among mature cells. Once infection spread to all erythrocytes, immature and mature cells became deformed, 
TABLE I. - Range of sizes of infected and noninfected erythrocytes: Geckoes.

\begin{tabular}{|c|c|c|c|c|}
\hline & $\begin{array}{c}\text { Erythrocytes } \\
L \times W\end{array}$ & $\begin{array}{l}\text { Nucleus } \\
L \times W\end{array}$ & $\begin{array}{l}\text { Virosome } \\
L \times W\end{array}$ & $\begin{array}{l}\text { Vacuole } \\
L \times W\end{array}$ \\
\hline \multicolumn{5}{|l|}{ Oedura rhombifer } \\
\hline RBC o & $14-16 \times 7-10$ & $5-6.5 \times 3-5$ & & \\
\hline $\mathrm{RBC}+$ & $16-18 \times 11-12$ & $5-6 \times 3-6$ & 1.5-2 diam. & $6-10 \times 6-10$ \\
\hline \multicolumn{5}{|l|}{ Heteronotia binoei } \\
\hline $\mathrm{RBC}$ o & $16.5-21 \times 8.5-12$ & $7-8.5 \times 4.5-5$ & & \\
\hline $\mathrm{RBC}+$ & $15-18 \times 12-13$ & $6-9 \times 5-7$ & $1.5-4 \times 1.5-4$ & 1-4 diam. \\
\hline \multicolumn{5}{|c|}{ Phyllodactylus marmoratus } \\
\hline $\mathrm{RBC} o$ & $14-18 \times 7-10$ & not measured & & \\
\hline $\mathrm{RBC}+$ & $15-19 \times 11-13$ & $4-5 \times 2.5-4$ & 1.5-2 diam. & $3-12 \times 3-12$ \\
\hline immRBC o & $12-18 \times 11-12$ & $9-11 \times 8-9$ & & \\
\hline immRBC + & $13-20 \times 9-12$ & $3.5-10 \times 3.5-5$ & $2-6 \times 1.5-4$ & 2-10 diam. \\
\hline \multicolumn{5}{|c|}{ Tarentola mauritanica } \\
\hline $\mathrm{RBC} O$ & $16-20 \times 8-11.5$ & $6-7.5 \times 4-5$ & & \\
\hline $\mathrm{RBC}+$ & $15-20 \times 8-12$ & $5-9 \times 4-8$ & $1.5-3 \times 1.5-3$ & $2-8 \times 2-6$ \\
\hline \multicolumn{5}{|c|}{ Ptyodactylus hasselquistii } \\
\hline $\mathrm{RBC} \circ$ & $16-21 \times 9-11$ & $5-9 \times 4-5$ & & \\
\hline RBC 0* & $12-19 \times 6-11$ & $5-7 \times 4-6$ & \multicolumn{2}{|c|}{ *) Anisocytosis } \\
\hline $\mathrm{RBC}+(\mathrm{i})$ & $16.5-23 \times 7.5-13$ & $4-9 \times 3.5-6$ & 1-2 diam. & 0-2 diam. \\
\hline$R B C+(v)$ & $16-21 \times 7-11$ & $3-10 \times 3-7$ & 1.5-3 diam & $2.5-8 \times 2.5-7$ \\
\hline EB o & $10-14 \times 8-10$ & $8-9 \times 8-9$ & & \\
\hline $\mathrm{EB}+$ & $9-18 \times 7-12$ & $5-9 \times 2-8$ & $(1) 3-6 \times 1-5$ & $0-8 \times 0-8$ \\
\hline PRBC o & $12-19 \times 7.5-10$ & $7-9 \times 5-7$ & & \\
\hline PRBC + & $16-18 \times 7-9$ & $5-7.5 \times 3-6.5$ & $1.5-4 \times 1.5-4$ & 1.5-4 diam \\
\hline
\end{tabular}

TABLE II. - Range of sizes of infected and noninfected erythrocytes: Agamid lizards and frogs.

\begin{tabular}{|c|c|c|c|c|}
\hline & $\begin{array}{l}\text { Erythrocytes } \\
\qquad \times \times W\end{array}$ & $\begin{array}{l}\text { Nucleus } \\
L \times W\end{array}$ & $\begin{array}{l}\text { Virosome } \\
L \times W\end{array}$ & $\begin{array}{l}\text { Vacuole } \\
L \times W\end{array}$ \\
\hline \multicolumn{5}{|l|}{ Agama impalearis } \\
\hline $\begin{array}{l}\text { RBC o } \\
\text { RBC + } \\
\text { RBC d + } \\
\text { Eb o } \\
\text { EB + } \\
\text { PRBC o } \\
\text { PRBC + }\end{array}$ & $\begin{aligned} 17-18 & \times 13-13 \\
9-16 & \times 6-9 \\
8-10 & \times 5-7 \\
14-17 & \times 11-13 \\
9-15 & \times 8-12 \\
12-18 & \times 9-12 \\
9-15 & \times 6-10\end{aligned}$ & $\begin{aligned} 5-6 & \times 5-5 \\
4.5-7 & \times 4.5-7 \\
3-5 & \times 3-4 \\
9-10 & \times 9-10 \\
4.5-8 & \times 4-8 \\
7-10 & \times 7-9 \\
5-9 & \times 4-7\end{aligned}$ & $\begin{array}{l}1-3.5 \text { diam } \\
1.5-3 \text { diam } \\
1.5-5 \text { diam. } \\
1.5-5 \text { diam }\end{array}$ & \\
\hline \multicolumn{5}{|l|}{ A. atra } \\
\hline $\begin{array}{l}\mathrm{RBC} o \\
\mathrm{RBC}+\end{array}$ & $\begin{array}{l}12-19 \times 9-11 \\
11-19 \times 8-14\end{array}$ & $\begin{array}{l}6-8 \times 4-5 \\
5-8 \times 4-5\end{array}$ & $1.5-4 \times 1.5-3$ & \\
\hline \multicolumn{5}{|l|}{ Limnonectes sp. } \\
\hline $\begin{array}{l}\mathrm{RBC} o \\
\mathrm{RBC}+\end{array}$ & $\begin{aligned} 19-22 & \times 11-13 \\
13.5-18 & \times 8-12\end{aligned}$ & $\begin{array}{l}6-9 \times 4-5 \\
5-7 \times 3.5-4\end{array}$ & $2-2.5 \times 1.5-2.5$ & \\
\hline \multicolumn{5}{|c|}{ Ptychadema anchietae } \\
\hline $\begin{array}{l}\text { RBC o } \\
\text { RBC + } \\
\text { immRBC } 0 \\
\text { immRBC + } \\
\text { immRBC d+ }\end{array}$ & $\begin{array}{c}15-17 \times 9-11 \\
17-20 \times 9-13 \\
\text { not measured } \\
10-18 \times 5.5-12 \\
6-9 \times 6-7\end{array}$ & $\begin{aligned} 5-7 & \times 2-3.5 \\
6-9 & \times 5-8 \\
6-10 & \times 4-9 \\
3-8 & \times 3-4\end{aligned}$ & $\begin{array}{l}1-3 \times 1.5-2.5 \\
2-6 \times 2-5 \\
2-3 \times 1-3\end{array}$ & \\
\hline
\end{tabular}

RBC, mature erythrocytes; EB, erythroblasts; immRBC, immature erythrocytes; PRBC, polychromophilic and pre-erythrocytic stage ; $o$, noninfected; + , infected. $d$, degenerate; $i$, no, or small vacuole, $v$, large vacuole. 

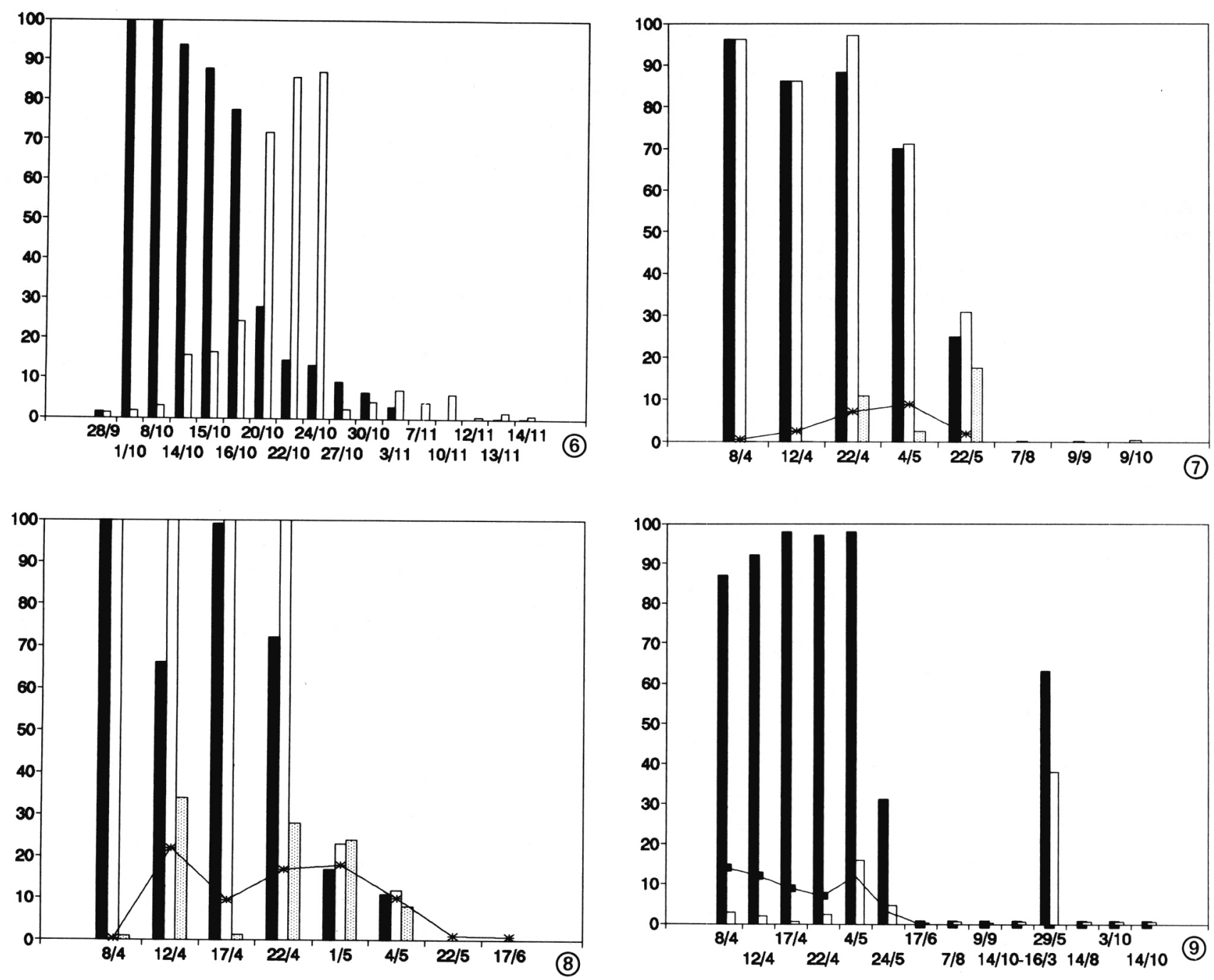

FIG. 6 to 9. - Course of erythrocyte infection (black) and occurrance of immature erythrocytes (white) in a captive P. hasselquistii. Y-axis: prevalence (\%) in the total RBC count, X-axis: dates. Figs. 7, 8. Total rate of erythrocyte infection (black), prevalence in mature erythrocytes only (white), occurrance of immature erythrocytes (spotted) and \% of infected erythrocytes with vacuoles (graph) in captive $P$. hasselquistii. Y-axis: prevalence $(\%)$ in the total RBC count, X-axis: dates. Fig. 9. Double infection of Pirhemocyton (histogram) and $\boldsymbol{H}$. ptyodactyli (graph) in captive $P$. hasselquistii: Infection rate of all erythrocytes (black), of mature erythrocytes only (white), and prevalence of immature erythrocytes (spotted). Y-axis: prevalence (\%) in the total RBC count, X-axis: dates.

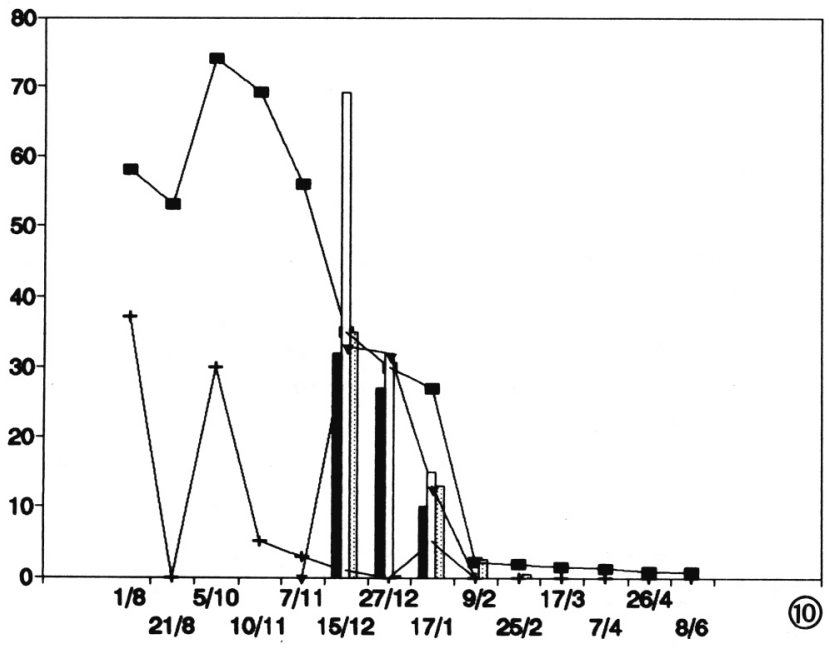

Fig. 10. - Double infection of Pirhemocyton (histogram) and $H$. gehyrae (graphs: square, total parasitemia, + , prevalence of juvenile stages, triangle, ratio of erythrocytes with mixed infections) in captive G. australis: Infection rate of all erythrocyte (black), of mature erythrocytes only (white), and prevalence of immature erythrocytes (spotted). Y-axis: prevalence $(\%)$ in the total $\mathrm{RBC}$ count, $\mathrm{X}$-axis: dates. 
degenerated and given rise to atropic erythrocytes. However prevalence of atrophic cells, with few exceptions, did not exceed $5 \%$ in the infected lizards.

\section{CRISIS}

A critical hematological condition seemed to develop when many or all erythrocytes had become infected. Increasing numbers of immature erythrocytes appeared, as well as immature cells undergoing mitosis, apparently to compensate for the presumed continuous loss of infected erythrocytes. This condition usually developed three weeks to one month after the appearance of the initial infection (Figs. 6, 15), but could take as long as six weeks. At the climax of immature cell proliferation, large proerythroblasts and erythroblasts prevailed (Figs. $1 A, B, E, F, 3 F, G, 4 J, K$ ). The accelerated erythropoiesis was characteristically coupled with marked anisocytosis, many erythrocytes failing to reach normal size. The proportion of immature erythrocytes increased from $<1 \%$ (« normal » value) to $5-35 \%$, and in some instances to above $50 \%$ (Figs. 6-15). In Toddia infections of frogs, the number of immature erythrocytes was already increasing (to $17 \%$ ) at low levels of erythrocytic infection (18\%) (see also Fig. 16). Only a fraction of the proliferating immature erythrocytes in geckoes became infected, while in $A$. impalearis about half did (Figs. $4 \mathrm{~J}, \mathrm{~K}, 11$ ). Almost all immature cells in frogs infected with Toddia became infected (98-100 \% vs. 22-28\% among mature cells in $P$. anchietae; (Fig. 5 F). During the crisis, the remaining mature and aged erythrocytes of $P$. hasselquistii contained in variable proportions either a large inclusion body and a vacuole loaded with virions (10-20 \% of the infected erythrocytes; Figs. 7,8$)$, or small inclusions with few or no virions (Fig. $3 \mathrm{H}$ ). In all other geckoes at crisis, all infected mature erythrocytes contained vacuoles.

Most naturally infected lizards which were being monitored in captivity survived infection. A. impalearis, which ultimately succumbed to the infection, demonstrated the most extreme hematological changes. During a one-month period of $99 \%$ infected mature erythrocytes (Fig. 4 D, I) the number of immature erythrocytes increased from 11 to $72 \%$ ( $42 \%$ infected; Fig. 11), and anaemia was evidented by the pale-transparent color of the blood (facilities for a hematocrit check were unavailable). When the animal died, $96 \%$ of the infected mature and $63 \%$ of the infected immature erythrocytes had degenerated (Fig. $4 \mathrm{~J}-\mathrm{L}$ ). Hematological crisis was far less apparent in the only $T$. hasselquistii which died infected: although all mature erythrocytes were infected, the number of immature erythrocytes did not exceed $14 \%$ (Fig. 3 F).

\section{RECOVERY:}

In all but two lizards followed up in captivity infection levels subsided within a month to six weeks. Crisis state was followed by infection regression, and the reappearance of newly generated, noninfected mature erythrocytes. At this stage the erythropoietic proliferative process subsided and ratio of immature erythrocytes declined to pre-crisis levels (Figs. 6-10, 12-16).

The regenerating erythrocytes only exceptionally became infected. The new erythrocyte generation gradually replaced the infected, aged, erythrocytes with a consequent decline or elimination of infection (Figs. 6, 9).

In some of the aged, degenerating, infected erythrocytes, inclusions seemed to disaggregate, prior to the ultimate degradation of the cell (Fig. 31). Such cells, were, however, rare (less than $0.1 \%$ ) and of little significance in the recovery process.

\section{Chronic ANd LATENT INFection}

In $P$. hasselquistii, a few erythrocytes with disaggregating inclusions and residual small vacuoles were traced for some time after regression of the massive infection. Latent low infections (0.1-1.5\%) of erythrocytes with a small intact inclusion, as seen in the initial infections (Figs. $3 \mathrm{H}, 4 \mathrm{~A}$ $C, 5 A, B$ ) remained from one to several months in $P$. hasselquistii, G. variegata, M. capensis, A. atra and the Limnonectes sp. frog.

\section{INCUBATION PERIOD AND RELAPSE}

Five $P$. hasselquistii, seemingly noninfected at capture developed erythrocytic infection within a period of one month to six weeks. Additional specimens developed infection five month and one year after capture. In three $P$. hasselquistii which were caught infected and recovered in captivity, infection relapsed in the following year to low-moderate levels with mildly enhanced erythropoiesis (Fig. 9). All delayed and recurrent infections appeared in 1991 in May, coinciding with the time of appearance of Pirhemocyton in 1991 in free ranging $P$. hasselquistii in the Lower Jordan valley. In 1990, infection appeared in free ranging geckoes already in April (Figs. 7-9). G. australis, the only other host lizard kept for a prolonged time in captivity, was free of infection at capture and developed an erythrocytic viral infection after four month (in December; Fig. 10).

\section{Concomitant infection with Haemoproteus SPP.}

Natural mixed infection involving both Pirhemocyton and species of Haemoproteus were found in one G. australis (with $H$. gehyrae; Figs. $1 \mathrm{H}, I$ ), in $4 P$. hasselquistii (H. ptyodactyli) and in one T. mauritanica ( $H$. tarentolae; Fig. 2 A) (Paperna and Landau, 1991). In all mixed infections except that of $G$. australis, parasites disappear with the decline in viral infection (Figs. 9, 13). In one P. hasselquistii, Haemoproteus, however, reappeared two weeks later. In all $P$. hasselquistii and in T. mauritanica, Haemoproteus occurred only in virally infected mature cells, while 
it occurred in none of the newly generated young erythrocytes replacing the infected cells. In $G$. australis, with termination of the viral infection, Haemoproteus parasitemia subsided from $37-27 \%$ to $2.6 \%$, then further to $<0.5 \%$, within the next fixe months (Fig. 10). In the infected $G$. australis, with $32-44 \%$ viral infection and 23-44 \% parasitemia only $2.6-16 \%$ were concomitant. Hematological changes dues to the viral infection did not interfered with concurrent Schellackia infections.

\section{DISCUSSION}

Toddia, found in frogs (Johnston, 1975) and snakes (Marquardt and Yaeger, 1967; Sousa et al., 1973), clearly differs from the Pirhemocyton-like erythrocytic viral infections of lizards, by the presence of a crystalloid body, also demonstrable ultrastructurally (Sousa and Weigl, 1976; Alves de Matos and Paperna, 1990). In lizard infections, the presence of a vacuole (= albuminoid body), during at least part of the viral infection process, or its total absence, corresponded vith distinct groups of hosts namely: vacuoles were present in all gecko infections, and absent in infections of agamids and skinks. Earlier data confirm this observation: Vacuoles have been consistently reported from gecko infections (Chatton and Blanc, 1914; Mackerras, 1961; Stehbens and Johnston, 1966), and were absent in an infection in the Australian skink Egerina striolata (Johnston, 1975). Among lizards of other taxa found infected, vacuoles similar to those found in gecko infections have been found to accompany infection of Eremias guttulatus olivieri (Blanc and Ascione, 1959), Cordylus vittifer (Pienaar, 1962), and chameleons (Brygoo, 1963) and were lacking in infections found in Lacerta viridis (P. lacertae of Brumpt and Lavier, 1935), and Takydromous takydromoides (Telford, 1972, 1984).

The same icosahedral virus which resembles DNA iridoviruses, has been demonstrated in infections of several species of geckoes, including, T. mauritanica, the type host of P. tarentolae (Stehbens and Johnston, 1966; Rioux et al., 1979; Alves de Matos and Paperna, 1990 and unpublished),
A. impalearis (Alves de Matos and Paperna, 1990 and unpublished) and in Toddia infections of frogs (Sousa and Weigl, 1976; Gruia-Gray et al., 1989; Alves de Matos and Paperna, 1990 and unpublished). Despite apparent similarities, differences noted by using light microscopy have been further substantiated at the ultrastructural level (Alves de Matos and Paperna, 1990). The light microscopic and fine structural data thus far obtained to date do not support conspecificity among infections of either Toddia or and Pirhemocyton from hosts of different genera (and geographical regions), as claimed by Blanc and Ascione (1959) or Mackerras (1961).

Pirhemocyton-like infections seem to become established in both immature and mature erythrocytes, while Toddia infection of frogs seems to become established in the erythrocytes before they mature. Neither light microscopic nor electron microscopic data (Alves de Matos and Paperna, unpublished) has been able to show whether proerythroblasts or erythroblasts contract infection in the haematopoietic tissue, or only after entering the circulation. It is also not certain if infected immature erythrocytes of reptiles are still able to differentiate into mature cells since they become severely deformed, and atrophic.

It seems likely that infection may become limited when the erythrocyte's synthetic machinery is lost during erythrocyte maturation. If this is so, erythroblasts could potentially synthesize large amounts of viral material (having large inclusions), pre-erythrocytes less because most ribosomes are lost, and mature erythrocytes would be unable to support much viral replication (having small inclusions). In such a system of differentiating cells, immature cells would develop stronger infection and be eliminated; more differentiated cells would be less affected and survive longer; infection established in fully differentiated or even aged erythrocytes would remain low-productive, becoming prolonged and latent.

The acute stage of natural infections in all observed lizard hosts lasted from one month to six weeks. The acute infection induced a state of crisis after all circulating erythrocytes became infected, and hematopoiesis was enhanced to compensate for the loss of the infected erythrocytes. Recovery

FIG. 11 to 16. - Crisis process in infected A. impalearis: Infection rate of all erythrocyte (black), of mature erythrocytes only (white), prevalence of immature erythrocytes (spotted) and their infection rate (oblong lines). Y-axis: prevalence in $\%$ in the total RBC count, X-axis: dates. Fig. 12. Infection in $\mathrm{H}$. binoei: Infection rate of all erythrocytes (black), of mature erythrocyts only (White), and prevalence of immature erythrocytes (spotted). Y-axis: prevalence (\%) in the total RBC count, X-axis: dates. Fig. 13. Pirhemocyton (histogram) and $H$. tarentolae (graph) mixed infection in $T$. mauritanica: Infection rate of all erythrocytes (black), of mature erythrocytes only (white), and prevalence of immature erythrocytes (spotted). Y-axis: prevalence (\%) in the total RBC count, X-axis: dates. Figs. 14, 15. Infection in T. mauritanica: Infection rate of all erythrocytes (black), of mature erythrocytes only (white), and prevalence of immature erythrocytes (spotted). Y-axis: prevalence (\%) in the total RBC count, X-axis: dates. Fig. 16. Infection in Limnonectes sp.: Infection rate of all erythrocytes (black), of mature erythrocytes only (white), and prevalence of immature erythrocytes (spotted). Y-axis: prevalence (\%) in the total RBC count, X-axis: dates. 

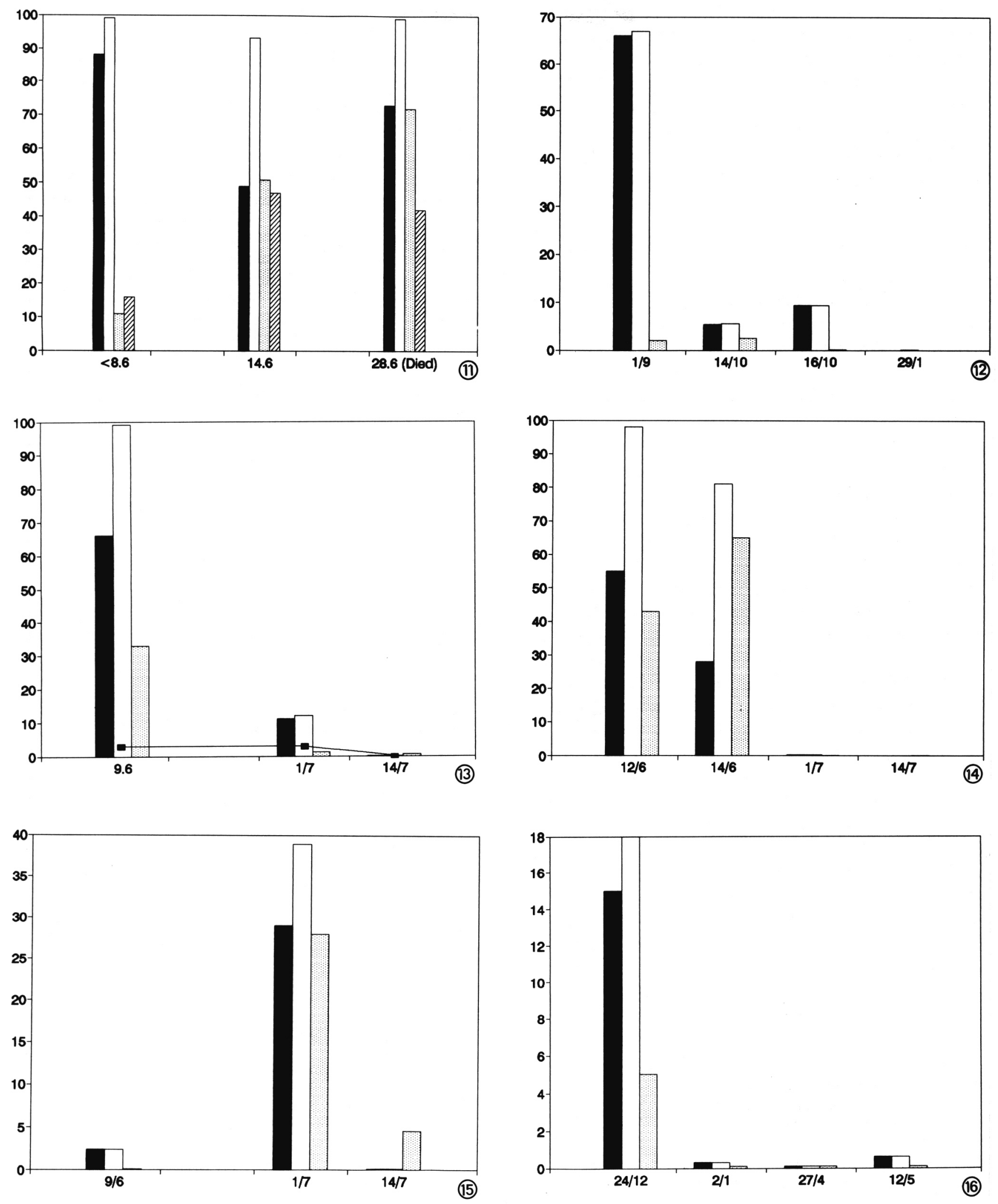

FIG. 11 
occurred when the infected cells perished and were replaced by a new generation of erythrocytes. This new generation remained uninfected, despite the presence of residual chronic infection in aged erythrocytes. The causes of the regression of viral infection remains unknown.

This process seems to be the same in all Pirhemocyton infections studied to date in free-ranging as well as captured reptiles. It is, however, not certain if the acute process of infection with Toddia in frogs is the same as in the reptilian Pirhemocyton. In the former hematopoiesis is activated before all mature erythrocytes have become infected. Previous studies of infection in T. mauritanica (Wood, 1935), C. vittifer (Pienaar, 1962), and T. takydromoides (Telford, 1984) describe similar erythrocytopathies caused by the viral infection, proliferation of immature erythrocytes and anisocytosis.

Course of hematological events in Pirhemocyton infections, leading to anaemia and crisis, closely resembles parasitic erythrocytic infections such as malaria. In malaria, of mammals and birds, erythrocytes are initially destroyed by release of merozoites. Later in the course of infection, the host response changes and many parasitized erythrocytes also become phagocytised (Kreier and Leste, 1967). In bird malaria, damaged erythrocytes are also eliminated by intravascular hemolysis (Seed and Manwell, 1977). Ultrastructural studies demonstrate some phagocytic activity in Pirhemocyton and Toddia infections (Alves de Matos and Paperna, unpublished), but most erythrocytes are lost apparently due to the direct impact of the viral infection. In the viral erythrocytic infections like in malarial parasitaemias, a compensating hematopoiesis follows the severe crisis. In mammalian infection, stimulation of hematopoiesis due to anaemia results in reticulocytosis (Topley et al., 1970). In lizards, severe anaemia, call into play a special mechanism permitting erythrocyte replacement directly from stem cells source - the hyperplastic post crisis blood picture contains cells in mitosis as well as the entire sequence of forming erythrocytes (Piennar, 1962, Ayala, 1977). Blood picture following Pirhemocyton induced crisis is the same as that induced by reptile malaria hematological crisis (Scorza, 1971).

Post crisis decline in erythrocytic infection, leading to latent (and cryptic) infection which can relapse in the due season is another feature common to haemoparasites, notably Plasmodium spp. (Telford, 1972, Coatney, 1976, Bromwich and Schall, 1986) and Pirhemocyton infections. The latent Pirhemocyton inclusions seen in chronic low infection are the apparent analogues of the hypnozoites of plasmodial infections of mammals (Krotoski et al., 1980) and reptiles (Telford, 1989).

In double infections involving Pirhemocyton and Haemoproteus, the parasites are lost when the virally infected generation of erythrocytes is replaced by new ones at postcrisis stage. Such was the case with $P$. hasselquistii and
T. mauritanica infected with Haemoproteus which were not recrudescing. Haemoproteus in a concomitant infection in G. australis declined but did not become eliminated, because the viral infection was moderate and there was still a continuous generation of young parasites, reestablishing themselves in the newly generated erythrocytes after the crisis stage.

Aknowledgements. - We wish to thank Drs. Bruce Copeman of the graduate School for Tropical Veterinary Sciences at James CoOK University of North Queensland and Peter J. O'Donoghue of the Central Veterinary Laboratories Adelaide, South Australia for their hospitality and support of our field work in Australia; Dr. Steve Donellan, South Australia Museum for his help in collecting reptiles and their identification; Pr. Rioux of the Laboratoire d'Écologie Médicale et de Pathologie Parasitaire, Faculté de Médecine, Montpellier, for providing us with Pirhemocyton infected A. impalearis and blood smear slides from Pirhemocyton infected T. mauritanica, and Dr. I. LANDAU Laboratoire de Zoologie (Vers) associé du CNRS, et Laboratoire de Protozoologie et Parasitologie Comparée, Museum National d'Histoire naturelle, Paris for support, laboratory facilities and good advice. Collection in South Africa was carried out during second author's CSIR-sponsored visit to the Zoology and Entomology Department of the Organge Free State University, Bloemfontein.

\section{REFERENCES}

Alves de Matos A. P., Paperna I. : Ultrastructure and viral nature of the " haemoparasites" Pirhemocyton and Toddia. I. LusoSpanish Congress of Herpetology, Lisbon, 1990 (Abstract).

Ayala S. C. : Plasmodia of reptiles. In: Kreier J. P., ed. Parasitic Protozoa, Vol. III, Academic Press, Inc., 1977, pp. 267-309.

Blanc G., Ascione L. : Sur un parasite endoglobulaire du lézard Eremias guttulatus olivieri Audoin, de la région de Marrakech. Arch. Inst. Pasteur Maroc., 1959, 5, 661-665.

Bromwich C. R., Schall J. J. : Infection dynamics of Plasmodium mexicanum, a malarial parasite of Lizards. Ecol., 1986, 67, 1227-1235.

Brumpt E., Lavier G. : Sur un hématozoaire nouveau du lézard vert Pirhemocyton lacertae n. sp. Ann. Parasitol. Hum. Comp., 1935, 13, 537-543.

Brygoo E. R. : Contribution à la connaissance de la parasitologie des Caméléons malgaches. Ann. Parasitol. Hum. Comp., 1963, $38,525-739$.

Chatton E., Blanc G. : Sur un hématozoaire nouveau Pirhemocyton tarentolae, du gecko Tarentola mauritanica. C. R. Soc. Biol., 1914, 67, 496-498.

Coatney G. R. : Relapse in malaria - an enigma. J. Parasitol., 1976, 62, 3-9.

Gruia-Gray J., Petric M., Desser S. : Ultrastructural, biochemical and biophysical properties of an erythrocytic virus of frogs from Ontario, Canada. J. Wildlife Dis., 1989, 25, 497-506.

Hawkey C. M., Bennett T. B. : Color Atlas of Comparative Veterinary Hematology. Iowa State University Press/Ames, 1989.

Johnston M. R. L. : Distribution of Pirhemocyton Chatton and Blanc and other, possibly related, infections of poikilotherms. J. Protozool., 1975, 22, 529-535.

Kreier J. P., Leste J. : Relationship of parasitaemia to Erythrocyte destruction in Plasmodium berghei infected rats. Expmt. Parasitol., 1967, 21, 78-83. 
Krotoski W. A., Krotoski D. M., Garnham P. C. C., Bray R. S., Killich-Kendrick R., Targett G. A. T., Guy M. W. : Relapse in primate malaria: discovery of two populations of exoerythrocytic stages. Br. Med. J., 1980, 1, 153-154.

Marquardt W. C., Yaeger R. G. : The Structure and Taxonomic Status of Toddia from the Cottonmouth Snake Ajkistrodon piscivorus leucostoma. J. Protozool., 1967, 14, 726-731.

Mackerras M. J. : The haematozoa of Australian reptiles. Aust. J. Zool., 1961, 9, 61-122.

Paperna I., Landau I. : Haemoproteus (Haemosporidia) of lizards. Bull. Mus. Nat. Hist. Nat., Paris, $4^{e}$ ser., 1991, 13 (section A), 309-349.

Pienaar U. V. : Haematology of some South African Reptiles. 1962, Witwatersrand University Press, Johannesburg.

Rioux J. A., Killick-Kendrick R., Garnham P. C. C. : Leishmania tarentolae and other blood parasites of geckoes at Banyuls in the south of France. Trans. R. Soc. Trop. Med. Hyg., 1979, $73,319$.

Scorza J. V. : Anaemia in lizard malaria infections. Parassitologia, 1971, 8, 391-405.

Seed T. M., Manwell R. D. : Plasmodia of birds. In: Kreier J. P. ed. Parasitic Protozoa, Vol. III, Academic Press, Inc., 1977, pp. 311-357.

Smail D. A. : Viral erythrocytic necrosis in fish: a review. Proc. Royal Soc. Edinburgh, 1982, 81, 169-176.

Sousa M. A., Biasi P., Pessoa S. B. : Protistas « incerta sedis» de ofideos do Brasil: Toddia Franca, 1912 e Pirhemocyton
Chatton and Blanc, 1914. Mem. Inst. Oswaldo Cruz, 1973, 71, 443-468.

Sousa M. A., Weigh D. R. : The viral nature of Toddia Franca, 1912. Mem. Inst. Oswaldo Cruz, 1976, 74, 213-230.

Stehbens W. E., Johnston M. R. L. : The viral nature of Pirhemocyton tarentolae. J. Ultrastr. Res., 1966, 15, 543-554.

Telford S. R. : The course of infection of japanese saurian malaria (Plasmodium sasai, Telford and Ball) in natural and experimental hosts. Japan. J. Exp. Med., 1972, 42, 1-21.

Telford S. R. : Haemoparasites of reptiles. In: Hoff G. L., Fry F. L., Jacobson E. R. ed. Diseases of Amphibians and Reptiles. Plenum Press, N. Y., 1984, pp. 285-517.

Telford S. R. Jr. : Discovery of the pre-erythrocytic stages of a saurian malaria parasite, hypnozoites, and a possible mechanism for maintanance of chronic infections throughout the life of the host. Int. J. Parasitol., 1989, 19, 597-616.

Topley E., Bruce-Chwatt L. J., Dorrel J. : Haematological study of a rodent malaria model. J. Trop. Med. Hyg., 1970, 75, 1-8.

Walker R., Sherburne S. W. : Piscine erythrocytic necrosis virus in Atlantic cod Gadus morhua, and other fish: ultrastructure and distribution. J. Fish Res. Board Can., 1977, 34, 11881195.

Wood S. F. : Variations in the cytology of the blood of geckoes (Tarentola mauritanica) infected with Haemogregarina platy dactyli, Trypanosoma platydactyli and Pirhemocyton tarentolae. Univ. Calif. Public. Zool. (Berkely), 1935, 41, 9-21.

Analyse.

G. A. T. TARGETT. - Malaria-Waiting for the vaccine, London School of Hygiene and Tropical Medicine. First annual Public Health Forum. John Wiley and Sons, London, 1991, 224 p.

The London School of Hygiene and Tropical Medicine decided to launch a series of Annual Public Health fora considering each year a major issue in public Health medicine. It chose as the subject of the first forum the very question of what to do now and in the near future about malaria, utilizing the means currently available. The title, Malaria-waiting for the vaccine, recognized that, though great hopes are pinned on the strenuous efforts being made to produce one or more vaccines, realistically these are still some years away, and something must be done in the meantime.

The book is the product of the forum and its special feature is the multidisciplinary approach to the problem. Thus there are contributions from the clinicians, laboratory scientists, epidemio- logists, and those concerned with the management and economics of health care programmes. In addition, the workshop summaries contain in total the carefully considered views and recommendations of 200 experts drawn from 54 countries. Finally, and appropriately there is a wise and stimulating postscript from Louis Miller.

This book should be read by everyone with a special interest in malaria or indeed in disease control generally. It first objective is to guide policy makers, not least the ministers of health of all countries, who need to make a special commitment to malaria control, in the ways and means to reverse the spread of the disease. At the practical level, those concerned with management of control programmes will find clearly stated and comprehensive recommendations. But, as important, every malariologist, from molecular biologist to social anthropologist, can benefit enormously from having his or her ideas broadned by reading this book from cover to cover.

D. MAZIER 